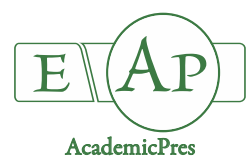

\title{
Investigation of Mineral and Vitamin C Contents in Different Parts of Beetroots (Beta vulgaris L.)
}

\author{
Dóra SZÉKELY*, Diána FURULYÁS, Mónika STÉGER-MÁTÉ \\ Szent István University, Faculty of Food Science, Department of Food Preservation, Villányi út 29-43, 1118 , \\ Hungary; babinszky-szekely.dora@etk.szie.hu ("correspondingauthor);furulyas.diana@etk.szie.hu; stegerne.mate.monika@etk.szie.hu
}

\begin{abstract}
Due to the increasing popularity of today's health-conscious culture, beetroot plays an increasingly important role in a healthy, varied diet. While it contains vitamins B1, B2, B6, P, as well as high levels of vitamin C, several studies have proven its role in the prevention of many cancers. The aim of this study was to compare morphological properties, dry matter, and vitamin $\mathrm{C}$ and minerals contents in the different parts (peel, end, middle and top part of root) of the three investigated beetroot cultivars grown in treated and untreated soil. Fertilizer was added to the treated soil before sowing of the beet seeds, while untreated soil was not treated. The vitamin C contents were measured using HPLC method, while determination of element contents was determined with IPC-OES. The study showed that the beetroots grow in the treated soil had improved morphological properties, but a significant difference was not found. For Vitamin $\mathrm{C}$ and element contents $(\mathrm{Ca}, \mathrm{Cu}, \mathrm{Fe}, \mathrm{K}, \mathrm{Mg}$, $\mathrm{Mn}, \mathrm{Na}, \mathrm{P}, \mathrm{Zn}$ ), it was observed a high degree of diversity in the different beetroot parts and between the cultivation years. The aim of the study was to investigate the distribution of the examined parameters within the beetroot body in different beetroot cultivars observing the differences produced by the addition of fertilizer. Some elements were concentrated in the peel and top part such as $\mathrm{Ca}, \mathrm{Mn}$ and $\mathrm{Mg}$. The peel part of the beetroots contained relevantly higher Fe content than the top, middle and end part. Based on these results, significant differences were observed among the investigated beetroot cultivars regards of the body weight.
\end{abstract}

Keywords: dry matter content; fertilizer; mineral content; morphological properties; vitamin C

\section{Introduction}

Beetroot has been commonly used for food and beverage since the $3^{\text {th }}$ Century, however they have been grown for thousands of years for medical purposes (Yashwant, 2015). Beetroot, although not overly popular in Hungary, it is popular vegetable in many parts of the world. The beetroots are native to the Mediterranean region. Nowadays these are more popular and widely cultivated in Europe, America and throughout Asia (Zohary et al., 2012; Chawla et al., 2016). Its maturity is reached in 75-90 days and during the cultivation their sugar content depends on the nitrogen availability so nitrogen is applied in the early stages of growth (Yashwant, 2015).

The food industry use the beetroot extract as a food colorant or additive as it improves the redness of different food products (Azeredo, 2009; Shing and Hathan, 2014; Chhinkara et al., 2019). The valuable colour contents of the beetroot are nitrogen-containing, water-soluble pigments, these are the betalaines. These can be divided into two main groups; the betacyanins (red-violet pigments) and the betaxanthins (yellow-orange pigments). The major betacyanin pigment in the beetroot is betanin, which is a betanidin-5-O- $\beta$-glucoside. The betanidin is the aglyconic form of the betanin. The major betaxanthin is the vulgaxanthin in the red beet (Delgano-Vargas et al., 2000; Stintzing and Carle, 2004; Kugler et al., 2007).

Beetroot juices are very valuable customer products, mainly due to the presence of numerous bioactive compounds (Kazimierczak et al., 2016). Beetroot consists of highly active compounds such as ascorbic acid (Clifford $e t$ al., 2015), betalains (Guldiken et al., 2016), carotenoids (Dias et al., 2009; Ninfali and Angelino, 2013; Rebecca et al., 2014), saponins (Atamanova et al., 2005; Mroczek et al., 2012), polyphenols and flavonoids (Váli et al., 2007; Lidder and Webb, 2013). Some bioactive compounds have been found in low levels such as glycine, betaine (Zwart et al., 2003) and folate (Jastrebova et al., 2003). Early studies reported that beetroot includes different type of vitamins such as vitamin A $(2 \mu \mathrm{g})$, thiamine $(0.31 \mathrm{mg})$, riboflavin $(0.27 \mathrm{mg})$, niacin $(0.331 \mathrm{mg})$, pantothenic acid $(0.145 \mathrm{mg})$, vitamin B6 (0.067 mg), ascorbic acid $(3.6 \mathrm{mg})$, folate $(80 \mu \mathrm{g})$ 
616

and minerals such as sodium (77 mg), calcium (16 mg), iron (0.79 $\mathrm{mg}$ ), phosphorus (38 mg), potassium (305 $\mathrm{mg}$ ), magnesium $(23 \mathrm{mg})$ and zinc $(0.35 \mathrm{mg})$ per $100 \mathrm{~g}$ of edible portion (Yashwant, 2015). Significant amount of sucrose is also proved by a study, in which the sugar content of various popular beetroot cultivars has been investigated. The average sugar content of seven tested beetroot cultivars was $77.5 \mathrm{gl}^{-1}$. The most amount of the sugar content was sucrose (94.8\%), followed by glucose $(3.3 \%)$ and fructose content was $1.9 \%$ (Wruss et al., 2015).

Consumption of beetroot reduces inflammation an innate response including inflection, erythema, edema, trauma, fever and pain that are caused due to cell damage by antigens (Monteiro and Azevedo, 2010). Also containing a powerful antioxidant, anti-inflammatory and vascularprotective properties, and its constituents have been clearly demonstrated by several in vitro and vivo human and animal studies (Váli et al., 2007; Clifford et al., 2015). The copper content of beetroot helps to make the iron more available to the body (Yashwant, 2015). Saponins can have an effective impact on different human cancers such as prostate, renal, breast, colon, lung, leukemia and melanoma (Podolak et al., 2010). According to the Váli et al. (2006) the beetroot can protect the entire body from the oxidative damage caused by ischaemia-reperfusion of the liver.

Sawicki et al. (2016) reported that red beetroot cultivars have their own batalain fingerprint as well as specific antioxidant capacity, which are also dependent on root part. During the investigation of 13 beetroot culivars the highest antioxidant capacity values were obtained for the peel, while the lowest was for the innermost ring of beetroots.

The aim of this work was to evaluate the distribution of dry matter, mineral and vitamin $\mathrm{C}$ content in difference beetroot parts as well as to assess the effect of fertilizer treatment in each part of different beetroot cultivars over two cultivation years while the fertilizer treatments had an effect to the certain parameters of plants. Ouda and Mahadeen (2008) reported that the dry matter content of broccoli shoots was not significantly affected by application of different fertilizers. The macro $(\mathrm{N}, \mathrm{P}, \mathrm{K})$ and the micronutrient ( $\mathrm{Fe}, \mathrm{Mn}, \mathrm{Zn}$ ) contents of their leaves increased with application of the fertilizers compared to the control.

\section{Materials and Methods}

\section{Biologicalmaterial}

In two consecutive years (2016 and 2017) the samples ('AltoF1', 'Cylindra' and 'Detroit') were cultivated in untreated and treated soil containing fertilizer made by Genezis (composition: 27\% nitrogen, 7\% calcium oxide and 5\% magnesium oxide) on the Experimental and Research Farm of Department of Vegetables and Mushroom Growing (Szent István University, Hungary). The infield can be classified as a rough sand soil type $(\mathrm{pH}=7.6)$. According to manufacturer's recommendation, $0.5 \mathrm{~kg}$ fertilizer was dispersed in $10 \mathrm{~m}^{2}$ soil. The ripening period took place from the end of April to end of July, approximately 100 cultivation days. There was no significant difference between the average temperatures in both years, and the amount of precipitation was compensated by irrigation. Ten beetroots were harvested randomly from different parts of the production area and each sample originated from one production area in order to have variations induced by different beetroot species and crop year, not by place of cultivation.

\section{Sample preparation}

After the harvesting and cleaning, the beetroot was peeled and divided into three parts thus providing four parts (peel, top, middle, end) which were separated from each other during the investigation.

\section{Determination of morphological properties and dry matter} content

In case of all beetroot cultivars, the body length and weight of 10 beetroots were measured. For determination of the dry matter content, the measurements were occurred using MB45 instrument manufactured by Ohaus.

\section{Determination of vitamin $C$ content}

For Vitamin $\mathrm{C}$ measurements, the eluens was $\mathrm{Na}$ acetate diammonium hydrogen phosphate solution ( $\mathrm{pH}=4.76)$. To the investigation, $2.5 \mathrm{ml}$ raw beetroot juice was mixed with $7.5 \mathrm{ml}$ extraction solution, which were allowed to rest for 15 minutes, then filtered through a streamer filter. The filtrates were passed through a membrane filter, so the samples were ready for injection. Five parallel measurements were performed per samples.

The measurements were performed according to method proposed by Maere (1988) using a Shimadzu HPLC device. To test of Vitamin C content with HPLC a reverse phase C18 column (Supelco, 250 x $4.6 \mathrm{~mm}$ i.d., 5 $\mu \mathrm{m})$ was applied. The column operates at $40{ }^{\circ} \mathrm{C}$ optimally. The adjusted parameters on the instrument were the flow rate: $1 \mathrm{ml} / \mathrm{min}$ (isocratic elution), the injected volume: 20 $\mu l$, the detection on 254 nanometers, and the measurement length: 4 minutes.

\section{Determination of element content}

Sample preparation was performed according to MSZ EN 13805: 2002, while the measurement according to EPA Method 6010C: 2007. Beetroot samples were air-dried at $60{ }^{\circ} \mathrm{C}$, and then all samples were pulverized. The powered samples $(0.2 \mathrm{~g})$ were digested in a mixture of $2 \mathrm{ml} \mathrm{HNO}_{3}$ a 2 $\mathrm{ml} \mathrm{H}_{2} \mathrm{O}_{2}$ in a Teflon holder and digested samples were then diluted with distilled water to a total volume of $10 \mathrm{ml}$. Before the measurements, the samples were filtered through a streamlined filter. The following elements were determined by inductively coupled plasma optical emission spectrometry (ICP-OES, IRIS Thermo Jarrel ASH, USA): As, $\mathrm{Ca}, \mathrm{Cd}, \mathrm{Cr}, \mathrm{Cu}, \mathrm{Fe}, \mathrm{Hg}, \mathrm{K}, \mathrm{Mg}, \mathrm{Mn}, \mathrm{Na}, \mathrm{P}, \mathrm{Pb}, \mathrm{Zn}$. The concentration of the elements is given as $\mathrm{mg} \mathrm{kg}^{-1}$.

\section{Statistical evaluation}

At least three analyses were run for each sample of morphological properties, dry matter, element content and Vitamin C concentration. Each analysis consisted of each sample and data were averaged over the three measurements. Data on the figures are presented as mean \pm standard deviation (SD). All statistical analyses were realized using SPSS Statistics v20 software. The statistical assessment 
was performed with analysis of variance (ANOVA). The transformation of the non-normal distribution of error elements was done by Box-Cox transformation. The deviation homogeneity test was carried out using the Levene test. The pairwise study was performed between the groups with a Tuckey test in the case of deviation homogeneity, otherwise the significant differences were checked with the Games-Howell test. On the figures black asterisk shows the parts of the beetroot cultivars that differ significantly from all other part values, so they do not belong to the same group on the basis of the post hoc test.

\section{Results and Discussion}

\section{Morphological investigation}

The body length and weight of the beetroots are shown in Fig. 1. There were no significant differences among the investigated years and treated-untreated versions in the average values of body weight, opposite there was significant difference between the years in the average values of body length $(\mathrm{p}=0.0006)$.

\section{Dry matter contents}

The distributions of dry matter content in the different beetroot parts are visible on Fig. 2. There was relevant difference only between the years by 'Detroit', where the dry matter content of the 2017 samples was significantly lower ( - $11.6125 \%)$ compared to the dry matter content of the 2016 samples $(\sim 16.22 \%)$, it means more than $28 \%$ decrease.

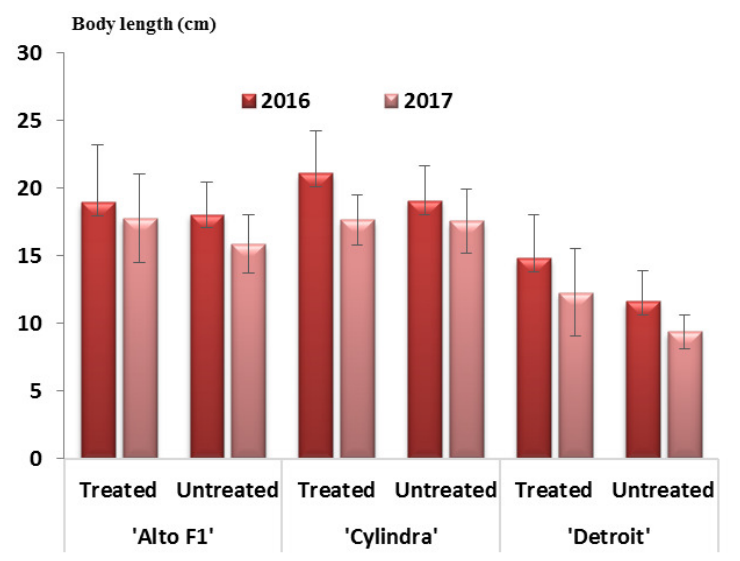

Fig. 1. Body length and weight of the investigated beetroots
For the effect of the treatment significant difference $(p=0.0181)$ was observed almost in 'Detroit' sample. Therefore, these treated samples had $14.73 \%$ of the average dry matter content while the untreated samples had $16.74 \%$.

\section{Element composition}

Mean macro- and microelement concentrations of different beetroot parts are shown in Fig. 3. The concentrations of $\mathrm{As}, \mathrm{Cd}, \mathrm{Co}, \mathrm{Cr}, \mathrm{Hg}$ and $\mathrm{Pb}$ were under the detection limit in each samples, which means that the investigated beetroot samples were free of toxic metals. For $\mathrm{Ca}, \mathrm{K}$ and $\mathrm{P}$ concentrations of the investigated the beetroot cultivars there were significant differences $(\mathrm{p}<0.05)$ between the two years. For effect of the treatment, significant difference was found in $\mathrm{K}$ content of 'Cylindra' in both years. Between the beetroot cultivars, there were significant difference in $\mathrm{Na}$ and $\mathrm{Zn}$ content.

Several studies have shown that the peel of beetroot was characterized by the largest betalain content (Kujala et al., 2002; Shing and Hathan, 2014; Slatnar et al., 2015; Sawicki et al., 2016).

In this study, similar tendency was observed for $\mathrm{Fe}$ concentrations. Relevantly higher amount of $\mathrm{Ca}, \mathrm{Mn}$ and $\mathrm{Mg}$ concentrations were found in the top and peel part of investigated beetroots, than in its middle and end parts.

Sawicki et al. (2016) also reported that there was significant difference among the investigated beetroot cultivars regarding the betalain content.
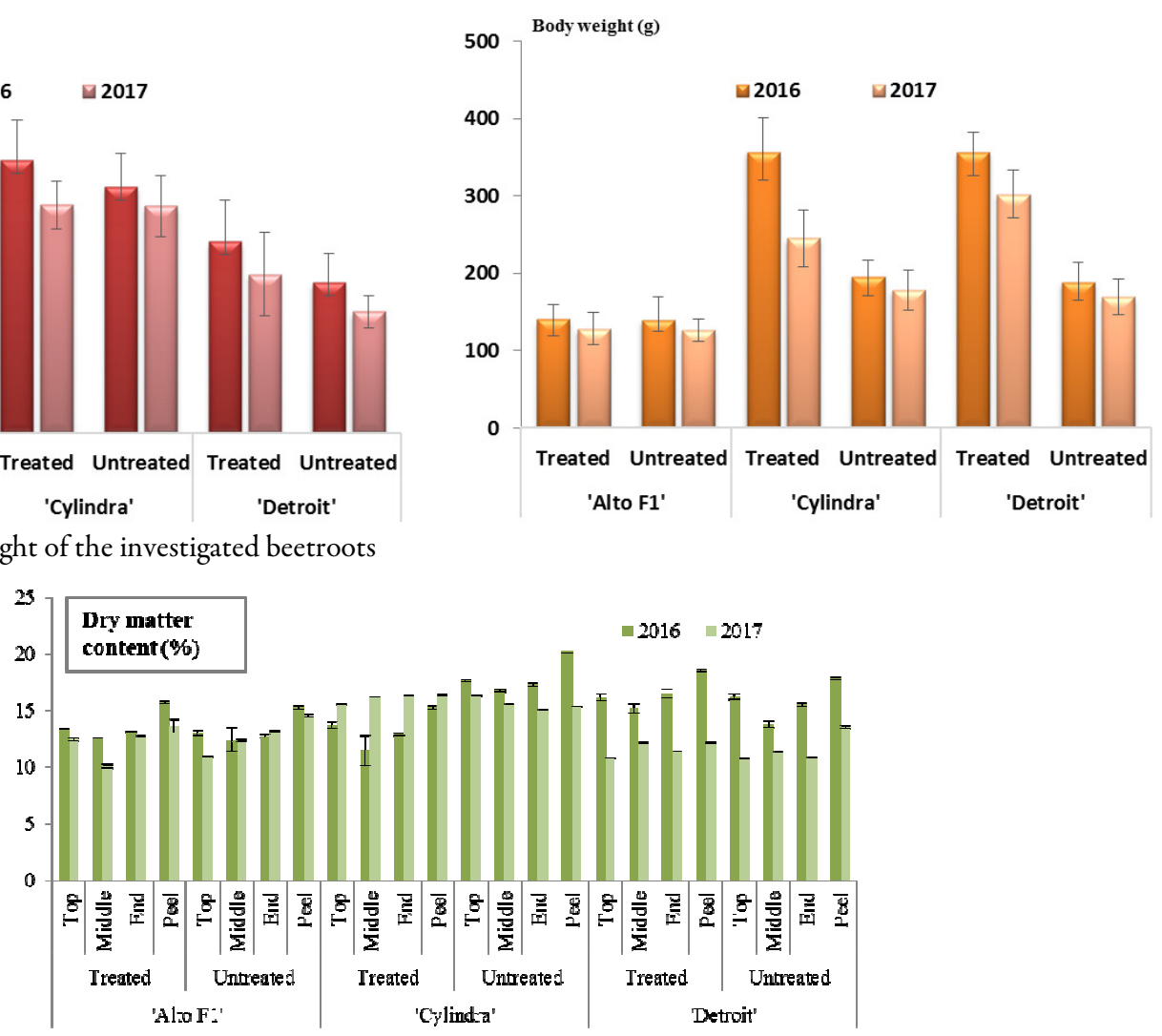

Fig. 2. Dry matter contents of the investigated beetroot cultivars 

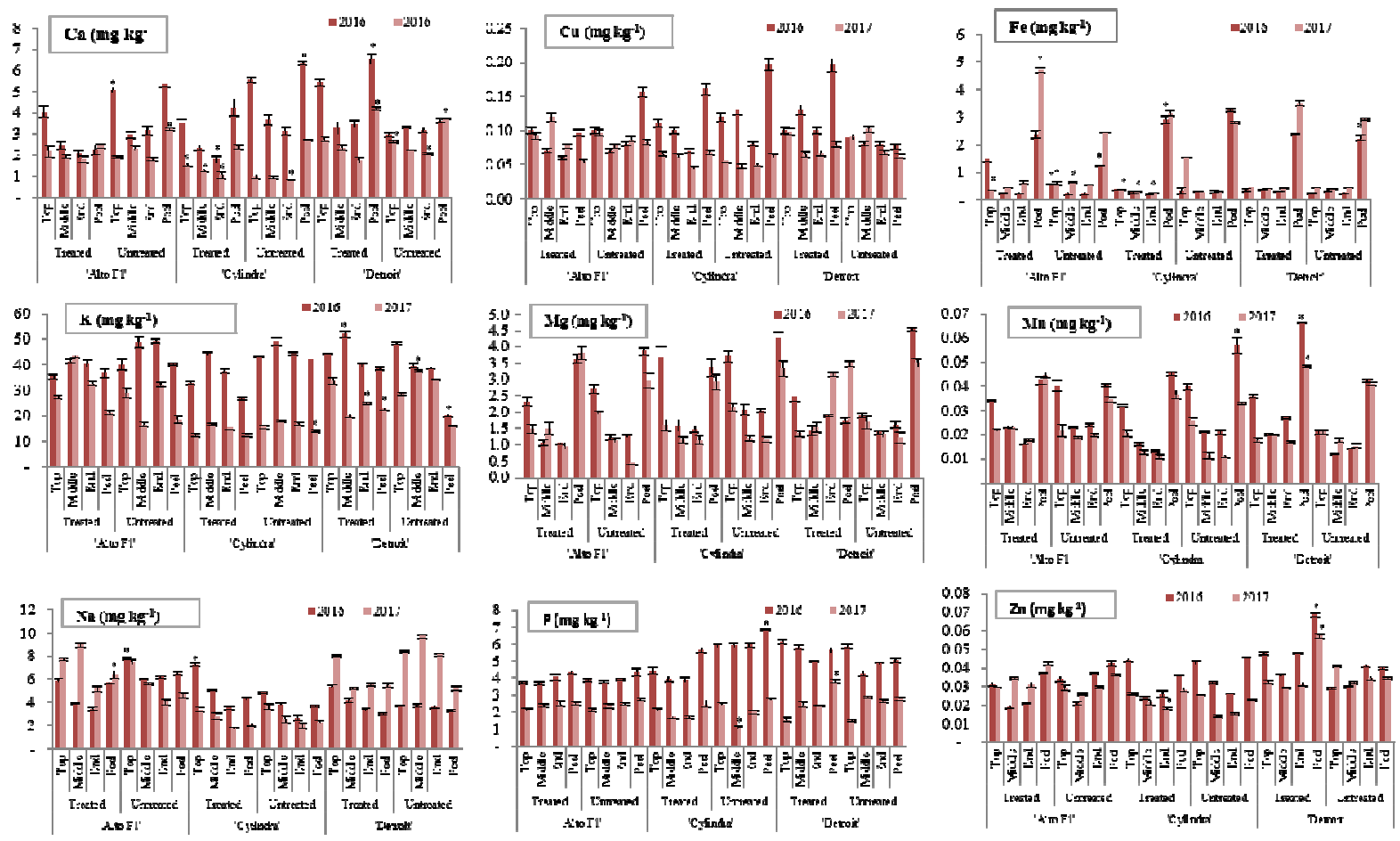

Fig. 3. Element concentrations of investigated beetroot cultivars

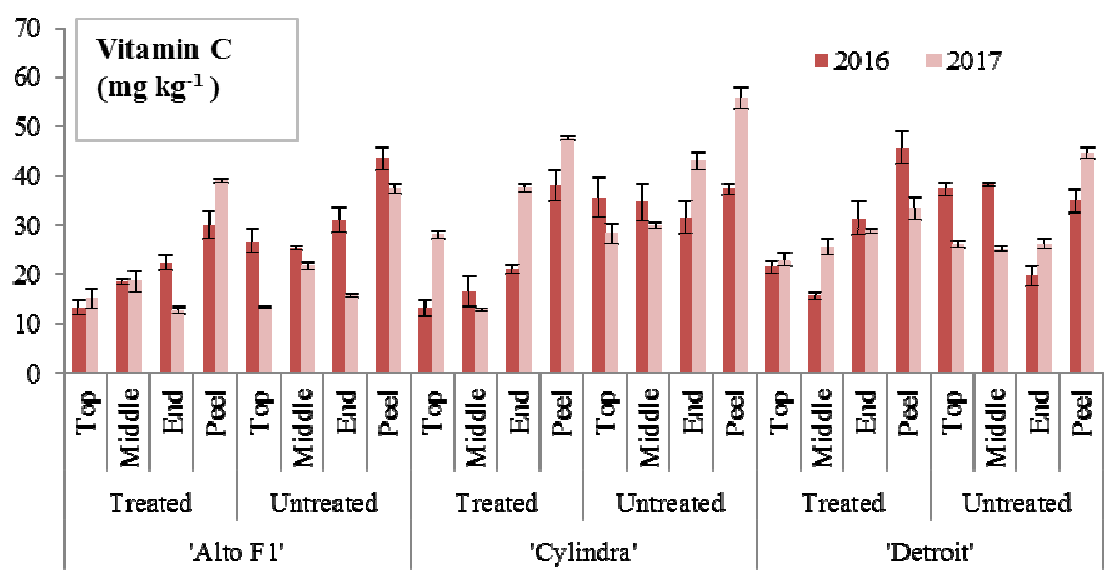

Fig. 4. Vitamin C concentrations of the investigated beetroot cultivars

Koczka et al. (2018) presented that the investigated parameters (some macro element, total phenolics and antioxidant capacity) were influenced less by the growing site, but rather by the genotype variance of wild and cultivated blackberries. Neményi et al. (2015) reported that the genetic factors and circumstance of cultivation had on effect on phytochemical content of bamboo shoots.

The measured element concentrations in this study are generally in good agreement with previously published data (Neelwarne, 2013; Wruss et al., 2015; Yashwant, 2015).

\section{Vitamin C content}

The Vitamin C concentrations of three different beetroot cultivars are presented in Fig. 4. There was no significant difference $(\mathrm{p}>0.05)$ between the cultivation years and treated-untreated versions. However, the Vitamin C content of 'Alto F1' and 'Cylindra' samples differed significantly from each other. Marked differences were noticed between the each beetroot parts. It could be observed, the vitamin $\mathrm{C}$ contents were concentrated in the peel parts in the most of cases. Similar concentrations to our data were reported for Vitamin C content by Yashwant (2015) and Neelwarne (2013). 


\section{Conclusions}

The measured values confirm that the investigated beetroot cultivars contain Vitamin $\mathrm{C}$ and certain minerals in large amount. Based on the result, in the most of cases the applied treatment has not significantly influenced morphological properties, dry matter, mineral and Vitamin $\mathrm{C}$ content. During the evaluation of the measured values it can be said that the distribution of investigated parameters showed relevant differences in each beetroot parts. In the peel parts the $\mathrm{Ca}, \mathrm{Fe}, \mathrm{Mn}, \mathrm{Mg}$ contents concentrated a higher amount in the three beetroots. $\mathrm{Ca}, \mathrm{Mn}$, and $\mathrm{Mg}$ contents are mainly accumulated in the top and end parts, whilst the highest Fe content was in the peel part in case of both cultivation vintages. Typically, the samples cultivated in 2016 had a higher mineral content, except for the $\mathrm{Na}$ and Fe content. The beetroots treated with fertilizer had a higher dry matter content and an average higher Fe content than untreated samples. In contrast, the untreated samples have significantly higher vitamin $\mathrm{C}$ content. Remarkable differences were obtained between the evaluated parameters regarding the cultivation years, which clearly indicates weather conditions are important factor during the cultivation of beetroots. Relevant differences were found between the investigated beetroot cultivations, so this study confirms that the choice of the species can be an important factor for food industry.

\section{Acknowledgements}

This work was supported by EFOP-3.6.3-VEKOP-162017-00005 and Doctoral School of Food Science Doctoral school ID: 232.

\section{References}

Atamanova A, Brezhneva TA, Slivkin AI, Nikolaevskii VA, Selemenev VF, Mironenko NV (2005). Isolation of saponins from table beetroot and primary evaluation of their pharmacological activity. Pharmaceutical ChemistryJournal 39(12):650-652.

Azeredo HMC (2009). Betalains: Properties, sources, applications and stability - A review. International Journal of Science \& Technology 44(12):2365-2376.

Chawla K, Parle M, Sharma K, Yadav M (2016). Beetroot: A health promoting functional food. Inventi Rapid: Nutraceuticals 1(1):09763872

Chhikara N, Kushwaha K, Sharma P, Gat Y, Panghal A (2019). Bioactive compounds of beetroot and utilization in food processing industry: A critical review. Food Chemistry 272:192-200.

Clifford T, Howatson G, West DJ, Stevenson EJ (2015). The potential benefits of red beetroot supplementation in health and disease. Nutrients 7(4):2801-2822.

Delgado-Vargas F, JiménezAR, Paredes-LópezO (2000). Natural pigments: Carotenoids, anthocyanins, and betalains - characteristic, biosynthesis, processing and stability. Critical Reviews in Food Science and Nutrition 40(3):173-289.

Dias MG, Camoes MFGFC, Oliveira L (2009). Carotenoids in traditional Portuguese fruits and vegetable. Food Chemistry 113(3):808-815.
Guldiken B, Toydemir G, Nur Memis K, OkurS, Boyacioglu D, Capanoglu E (2016). Home-processed red beetroot (Beta vulgaris L.) products: Changes in antioxidant properties and bioaccessibility. International Journal of Molecular Sciences 17(6):858.

JastrebovaJ, Witthoft C, Grahn A, Svensson U,Jagerstad M (2003). HPLC determination of folates in raw and processed beetroots. Food Chemistry 80(4):579-588.

Kazimierczak R, Siłakiewicz A, Hallmann E, Średnicka-Tober D, Rembiałkowska E (2016). Chemical composition of selected beetroot juices in relation to beetroot production system and processing technology. Notulae Botanicae Horti Agrobotanici 44(2):491-498.

Koczka N, Stefanovits-Bányia É, Prokaj E (2018). Element composition, total phenolics and antioxidant activity of wild and cultivated blackberry (Rubus fruticosus L.) fruits and leaves during the harvest time. Notulae Botanicae Horti Agrobotanici 46(2):563-569.

Kugler F, Graneis S, Stintzing FC, Carle R (2007). Studies on betaxanthin profiles of vegetables and fruits from the Chenopodiaceae and Cactaceae.Zeitschrift fur NaturforschungC 62(5-6):311-318.

Kujala TS, Vienola MS, Klika KD, Loponen JM, Pihlaja K (2002). Betalain and phenolic compositions of our beetroot (Beta vulgaris) cultivars. European Food Research and Technology 214(4):505-510.

Lidder S, Webb AJ (2013). Vascular effects of dietary nitrate (as found in green leafy vegetables and beetroot) via the nitrate-nitrite oxide pathway. British Journal ofClinical Pharmacology 75(3):677-696.

Maere R (1988). HPLC in food analysis. Academic Press, London, pp 172179.

Monteiro R, Azevedo I (2010). Chronic inflammation in obesity and the metabolic syndrome. Mediator of Inflammation doi: 10. 1155/2010 1289645 .

Mroczek A, Kapusta I, Janda B, Janiszowska W (2012). Triterpene saponin content in the roots of red beet (Beta vulgaris L.) cultivars. Journal of Agricultural and Food Chemistry 60(50):12397-12402.

Neelwarne B (2013). Red beet biotechnology. In: Food and Pharmacentical Applications. Springer Sciense and Business, New York, pp 199-243.

Neményi A, Stefanovits-Bányai É, PékZ, Hegedüs A, Gyuricza C, Barócsi Z, Helyes L (2015). Total antioxidant capacity and total phenolics content of Phyllostachys taxa shoots. Notulae Botanicae Horti Agrobotanici 43(1):64-69.

Ninfali P, Angelino D (2013). Nutritional and functional potential of Beta vulgaris cicla amd rubra. Fitoterapia 89:188-199.

Ouda BA, Mahadeen AY (2008). Effect of fertilizers on growth, yield, yield components, quality and certain nutrient contents in broccoli (Brassica oleracea). International Journal of Agriculture and Biology 10(6):627632.

Podolak I, Galanty A, Sobolewska D (2010). Saponins as cytotoxic agents: a review. Phytochemistry Reviews 9(3):425-474.

Rebecca J, Sharmila S, Das MP, Seshiah C (2014). Extraction and purification of carotenoids from vegetables. Journal of Chemical and Pharmaceutical Research 6(4):594-598.

Sawicki T, Baczek N, Wiczkowiski W (2016). Betalain profile, content and antioxidant capacity of red beetroot dependent on the genotype and root part. Journal of Functional Foods 27:249-261. 
620

Shing B, Hathan BS (2014). Chemical composition, functional properties and processing of beetroot - a review. International Journal of Scientific andEngineering Research 5(1):679-684.

Slatnar A, Stampar F, Vebaric R, Jakopic J (2015). HPLC-MS(n) identification of betalains profile of different beetroot (Beta vulgaris $\mathrm{L}$. ssp. vulgaris) parts and cultivars. Journal of Food Science 80(9):19521958.

Stintzing FC, Carle R (2004). Functional properties of anthocyanins and betalains in plants, food and in human nutrition. Trend in Food Science and Technology 15(1):19-38.

Váli L, Fébel H, Stefanovits-Bányai É, Sárdi É, Lugasi A, Szentmihályi K, Blázovics A (2006). Duodenum protecting effects of table beet (Beta vulgaris L. ssp. esculenta var. mubra) during hepatic ischaemia-reperfusion. ActaAlimentaria 35(4):445-453.

Váli L, Stefanovits-Bányai É, Szentmihályi K, Fébel H, Sárdi É, Lugasi A, Kocsis I, Blázovics A (2007). Liver-protecting effects of table beet (Beta vulgaris var. mbra) during ischemia-reperfusion. Nutrition 23(2):172178.
Wruss J, Waldenberger G, Huemer S, Uygun P, Lanzerstorfer P, Müller U, Höginger O, Weghuber J (2015). Compositional characteristics of commercial beetroot products and beetroot juice prepared from seven beetroot varieties grown in Upper Austria. Journal of Food Composition and Analysis 42:46-55.

Yashwant K (2015). Beetroot: A super food. International Journal of EngineeringStudies and Technical Approach 1:20-26.

Zohary D, Hopf M, Weiss E (2012). Domestication of plants in the old world: The origin and spread of domesticated plants in Southwest Asia, Europe, and the Mediterranean Basin. Oxford University Press.

Zwart FJ, Slow S, Payne RJ, Lever M, George PM, Gerrard JA, Chambers ST (2003). Glycine betaine and gycine betaine analogues in common foods. Food Chemistry 83(2):197-204. 